\title{
Novo coronavírus e os impactos causados pelo isolamento social sobre praticantes de voleibol
}

\author{
New coronavirus and the impacts caused by social \\ isolation on volleyball players
}

Hans Gert Rottmann ${ }^{1}$

RESUMO

Introdução: A gravidade ocasionada pela pandemia do novo coronavírus fez com que governantes e organizações de saúde se preocupassem em conter o avanço de contágio do vírus em todo o mundo, assim o isolamento social foi adotado como medida para evitar a Covid-19. Objetivo: A pesquisa trata sobre os impactos causados pelo isolamento social sobre praticantes de voleibol. Resultado: Envolvidos com o esporte por diferentes motivações, os praticantes de voleibol, ao suspenderem suas práticas, relataram prejuízos em aspectos ligados à qualidade de vida, saúde mental e física. Durante o isolamento social, os esportistas passaram a valorizar mais ainda suas atividades no voleibol, sendo que estas refletem na realização pessoal e felicidade destes.

PALAVRAS-CHAVE

Novo coronavírus; isolamento social; voleibol; impactos; esportes.

\footnotetext{
${ }^{1}$ Centro Universitário La Salle - Unilasalle.
} 


\section{ABSTRACT}

Introduction: The severity caused by the pandemic of the new coronavirus has made government and health organizations to be concerned about holding the spread of the virus worldwide, so social isolation was adopted as a measure to prevent Covid-19. Objective: The research is about the impacts caused by social isolation on volleyball players. Results: Involved with the sport by different motivations, the volleyball players, when suspending their practices, reported losses in aspects related to life quality, mental and physical health. During social isolation, athletes began to value their volleyball activities even more, and they reflect on their personal fulfillment and happiness.

\section{KEYWORDS}

New coronavirus; Social isolation; Volleyball; Impacts; Sports. 
Quando os primeiros casos do novo coronavírus ${ }^{1}$ foram confirmados na cidade de Wuhan, China, no final de 2019, poucas pessoas imaginariam que não tardaria para o vírus chegar ao Brasil. Apenas dois meses depois², porém, conforme o Ministério da Saúde, o vírus chegava ao país e em poucas semanas começava a se alastrar não somente nas grandes cidades, como também no interior de todos os estados, exatamente como uma pandemia. Medeiros (2020), ao comentar sobre a origem ainda não comprovada da Covid-19 por meio de uma mutação de um vírus que infecta morcegos, detalha o local onde ele teria surgido e rapidamente se alastrado:

O local inicial de transmissão foi um mercado de frutos do mar e animais vivos na cidade de Wuhan, China. Os primeiros casos foram de indivíduos frequentadores desse mercado. Posteriormente o vírus foi transmitido para familiares e, em progressão geométrica, para províncias próximas, expandindo-se para diversos países de todos os continentes (MEDEIROS, 2020, p.1).

De acordo com Benvenuto et. al. (2020), a transmissão do coronavírus é ocorrida por gotículas expelidas pela boca de alguma pessoa contagiada ou até mesmo por meio do contato físico com pessoas contaminadas. Outras pesquisas, porém, sugerem que a Covid-19 também pode ser transmitida pelo ar (LEWIS, 2020). Constata-se assim como a velocidade e contágio deste tipo de vírus é alta, pois apenas uma pessoa pode transmitir o vírus para outras duas, três ou mais pessoas.

O contato mais próximo com o vírus, seguido da preocupação com sua velocidade de contágio, refletiram de modo significativo no mundo todo, como é possível perceber a partir de um texto produzido pela Fundação Oswaldo Cruz:

a pandemia de Covid-19, causada pelo vírus SARS-CoV-2 ou Novo Coronavírus, vem produzindo reper-

1 De acordo com TAN, ZHAO \& MA (2020) apud Belasco e Fonseca (2020), o 2019-nCoV é chamado de Novel Coronavirus-Infected Pneumonia (NCIP). Este vírus também já foi descoberto em morcegos e outros animais selvagens, além dos humanos. No Brasil a nomenclatura mais utilizada é "novo coronavírus" e o nome dado a doença ocasionada pelo vírus, "Covid-19". 20 Ministério da Saúde confirmou no dia 26 de fevereiro de 2020 o primeiro caso do novo coronavírus em São Paulo, Brasil. A pessoa que deu entrada no hospital tinha recentemente retornando da Itália. cussões não apenas de ordem biomédica e epidemiológica em escala global, mas também repercussões e impactos sociais, econômicos, políticos, culturais e históricos sem precedentes na história recente das epidemias (OSVALDO CRUZ, 2020, p.1).

No Brasil, não diferentemente, a pandemia ocasionada pelo novo coronavírus influenciou diferentes esferas da sociedade e tem causado impactos fortes na economia, política, saúde pública e saúde mental de boa parte das pessoas.

Como medida para impedir a propagação do novo coronavírus ao redor do mundo, a Organização Mundial de Saúde - OMS e a Organização Panamericana de Saúde - OPAS destacaram desde o início da pandemia a importância do isolamento social. Ao tratar do avanço da pandemia no Brasil, até mesmo a Organização das Nações Unidas - ONU por meio de seu jornal digital, ONU News, reafirmou que "o aumento no número de casos de contaminação com o novo coronavírus, no Brasil, pode ser contido com mais isolamento social"(ONU, 2020, p.1). A partir disso, diversos governos municipais e estaduais passaram a lançar medidas de distanciamento social, tentando conter o avanço do contágio pelo vírus. Assim, passaram a ser restringidas atividades públicas e aglomerações. Na maioria dos locais houve suspensão temporária de serviços (escolas, serviços públicos não essenciais, comércio). Tais medidas foram tomadas para estimular as pessoas a permanecerem confinadas em suas casas (PIRES, 2020).

Informações obtidas no painel criado pelo Ministério da Educação, desenvolvido com o intuito de ser o veículo oficial de comunicação sobre a epidemia da Covid-19 no Brasil, e publicadas na data em que este artigo foi escrito, confirmavam que no país já haviam sido contagiadas 3.035.422 pessoas, sendo que apenas no dia anterior, 23.010 novos casos teriam sido registrados. 0 total de óbitos até então ${ }^{3}$ era de 101.049 (Disponível em: https://covid.saude.gov.br/, ago. 2020).

A restrição de contato entre pessoas por meio do isolamento social fez com que muitas pessoas deixaram de realizar parte de suas rotinas, sejam estas ligadas ao trabalho, estudo ou lazer. Nesse sentido, acredita-se que os praticantes de esportes possam ter sido um dos grupos que mais sentiram o afastamento de suas atividades,

3 Acesso em 10 de agosto de 2020. 
uma vez que as práticas esportivas ${ }^{4}$, principalmente as coletivas, foram suspensas em praticamente todo país.

A partir do contexto apresentado, o presente estudo buscou conhecer os impactos causados pelo isolamento social, provocados pelo novo coronavírus, sobre praticantes de voleibol.

A escolha por praticantes da modalidade esportiva "voleibol" se deu de maneira intencional e foi baseada em argumentos consistentes. 0 voleibol é reconhecidamente um dos esportes onde mais se observa o jogo coletivo. A disputa de apenas um único ponto pode envolver três, quatro ou cinco jogadores, mas não raramente todos os jogadores posicionados em quadra (12) participam da jogada antes da bola cair no chão. Diferentemente de outros esportes coletivos, onde um jogador pode ficar posicionado em seu lugar sem necessariamente participar ativamente do jogo, no voleibol todos jogadores precisam efetuar o rodízio, deslocando-se pelos espaços da quadra. Mais do que isso, todos os jogadores, exceto o líbero, devem realizar o saque. Outro fator considerado foi o fato do voleibol ser considerado no Brasil um esporte popular, ocupando a segunda posição entre os esportes mais praticados no país, atrás apenas do futebol (Alves, 2020). Estudiosos destacam a variedade de espaços e objetivos que podem ser encontrados em torno da prática do voleibol, quando afirmam:

\begin{abstract}
Atualmente o voleibol é uma das modalidades esportivas mais populares no Brasil. As suas práticas ocupam um cenário amplo de possibilidades que perpassam o conteúdo da educação física escolar, o desenvolvimento de valores sociais preconizados em projetos sociais, as atividades de lazer, o exercício físico voltado à manutenção da saúde e o rendimento em competições (MOREIRA et al., 2017, p. 121)
\end{abstract}

Entre as diversas finalidades em torno da prática deste esporte, essa pesquisa ocupou-se com informações provenientes de praticantes de voleibol da categoria adulto, de ambos os sexos, que faziam parte de grupos que praticavam esse esporte ou realizavam aulas e treinos pelo menos uma vez por semana no período de

4 Práticas esportivas individuais continuaram acontecendo durante a pandemia, como caminha, ciclismo e corrida. Nestes casos, houve normalmente recomendação para o uso da máscara para proteção e ainda a indicação para existir um distanciamento de pelo menos 2 metros de outras pessoas. chegada da pandemia da Covid-19 no país. Mesmo que estes grupos, por vezes são chamados de equipes, já que participam eventualmente de competições amadoras, não visam exclusivamente aspectos ligados a performance individual e coletiva. Seus jogos, torneios e eventos não são classificados como esporte de alto rendimento. Apesar disso, não há impedimento para que apresentem, não raramente, alguns elementos que possam se assemelhar ao treinamento de equipes profissionais. Notadamente se diferem, no entanto, em aspectos ligados à exigência física, técnica e tática, bem como em seus patamares de intensidade e volume apresentados nas atividades, treinos e jogos. Nestes grupos ou equipes, é possível dizer que as práticas esportivas são realizadas por diferentes fatores motivacionais, como o lazer, qualidade de vida, socialização, aprendizado, etc.

\begin{abstract}
O esporte é o exercício físico mais praticado por toda a sociedade brasileira, que pode ter diferentes objetivos para a sua prática (...). 0 esporte como lazer: objetiva um momento de alegria, descontração, a busca pela confraternização entre amigos e familiares, nem sempre segue as regras oficiais e muito menos é seletivo (ANJOS, 2008, p.1).
\end{abstract}

Cabe lembrar o que Bracht (1989) anunciou sobre o esporte, enquanto atividade de lazer, quando destacou que este pode ser praticado a partir de derivações do esporte de rendimento, o que permite entender, no contexto desta discussão, que outras possibilidades e formatos de jogos/atividades esportivas se oferecem. Em decorrência da pandemia e necessidade do isolamento social, é possível acreditar que os praticantes de voleibol, impossibilitados de praticar o jogo em seu formato convencional $^{5}$, podem ter criado ou recriado diversificadas formas para praticar o vôlei, até mesmo em casa, seja com seus familiares ou realizando atividades individualmente. Rottmann (2020), com o intuito de auxiliar pessoas que estariam impossibilitadas de praticar

50 voleibol de acordo com as regras oficiais deve ser disputado entre duas equipes compostas por 6 jogadores cada uma, em uma quadra lisa e livre de obstáculos. 0 formato de jogo, as regras sobre o manuseio da bola e qualquer tipo de regulamento ou regras pertinentes a esse esporte se encontram disponíveis no site da Confederação Brasileira de Voleibol. Disponível em: https://cbv.com.br/pdf/regulamento/quadra/REGRAS-DE-QUADRA-2017-2020.pdf. 
aulas ou treinos de voleibol no período do isolamento social, criou uma série de atividades em formas de desafios ligados a esse esporte para serem realizados em casa. Os desafios disponibilizados em vídeos nas redes sociais acabaram ganhando também repercussão na mídia televisiva ${ }^{6}$, despertando o interesse de esportistas no desenvolvimento de atividades ligadas ao voleibol adaptadas para fazer em casa. Manifestando sua preocupação com a saúde mental de esportistas que estariam impossibilitados de realizar suas práticas esportivas em decorrência do isolamento social, esse estudioso ao tratar sobre esportes sugeriu:

...como atuo com o vôlei, mas gosto de outros esportes, criei desafios combinando habilidades e fundamentos de diferentes modalidades. Através dos desafios, ocupei meu tempo, me desafiei, envolvi com atividades físicas e o melhor, mantive minha mente saudável e um pouco distante das preocupações (...) foram criados até agora mais de 20 desafios compartilhados nas redes sociais para que outros possam também tentar fazer (ROTTMANN, 2020, p. 12).

Conforme destacado antes, é possível imaginar que os praticantes de voleibol destes grupos praticam esta modalidade esportiva visando a qualidade de vida. Santos e Simões (2012) afirmam que existe uma ideia fortemente difundida na sociedade de que as atividades físicas e os esportes possuem influencia positiva na melhoria da qualidade de vida das pessoas. Realmente, há um número elevado de publicações que indicam que o esporte pode proporcionar qualidade à vida das pessoas.

Nesse sentido é preciso lembrar de que vários fatores podem determinar a qualidade de vida das pessoas. Ao avaliar a importância das atividades físicas e esportes nesse contexto, é preciso lembrar que, mesmo existindo um discurso generalizado que indique suas contribuições para ganhos físicos, bem-estar, saúde mental e convívio social, faz-se necessário compreender os tipos de atividades ou esporte em questão, o público alvo e ainda quais objetivos estariam ou não inseridos em sua prática. Somente assim torna-se possível estabelecer uma possível relação entre qualidade de vida, esportes e seus praticantes. Convêm ainda destacar que

6 Os desafios do vôlei foram exibidos no Programa Jornal do Almoço da RBS TV no dia 27 de meio de 2020. aspectos ligados ao volume, intensidade e frequência das atividades, aulas e treinos precisam ser avaliados e prescritos de maneira correta para que essa equação tenha um bom resultado.

Para que o esporte seja um fator de melhoria da Qualidade de Vida, o ideal de percepção na sociedade contemporânea é que seja incorporado como um dos muitos hábitos cotidianos ao estilo de vida dos sujeitos, não somente como um fator de consumo sedentário, mas como objeto de prática de atividade física, desde que adequado às necessidades, expectativas, possibilidades e limites do indivíduo (MARQUES, 2007, p. 135).

Em busca desta rotina e hábitos saudáveis ligados a pratica regular do voleibol que, eventualmente, parte destes sujeitos atuantes nestes grupos se encontra. Mesmo que possam existir diferentes expectativas e motivações entre seus participantes, a modalidade do voleibol termina sendo o caminho para estas. Ao contrário do que acontece no esporte de alto rendimento, com atletas profissionais, onde todos esforços caminham para o alcance do ótimo rendimento e conquista de vitórias, nestes grupos, vencer os jogos talvez tenham a mesma importância que o nível de satisfação de participar dos mesmos. Isso não quer dizer, no entanto, que não ocorram jogos e treinos disputados com valorização aos aspectos técnicos do voleibol, afinal, a competição e o desejo da vitória acaba sendo inerente ao esporte, mesmo no contexto do lazer. Como destacou Muniz (2010), não é incomum o esporte praticado em ambientes não profissionais acabar assumindo características do esporte de alto rendimento.

Ainda que estes espaços possam representar universos esportivos distintos, onde os participantes atribuem sentidos e significados diferentes ao esporte, fazendo deste uma prática heterogênea, ainda assim ele tem sido desenvolvido predominantemente de forma homogênea, centralizado no modelo esporte espetáculo (MUNIZ, 2010, p. 1).

Um entendimento mais simplório indica que, mesmo sendo a prática esportiva realizada por mera diversão, uma base mínima de técnica e de condição atlética se fará necessária para que esta prática possa acontecer de modo atrativo e desperte interesse em sua continui- 
dade. Por esta razão que a organização e condução destes grupos de voleibol, preferencialmente, deve ser realizada por um profissional da área da educação física que irá auxiliar no desenvolvimento das atividades e dirigi-las conforme as possibilidades existentes, bem como, com os diferentes objetivos que as pessoas ali presentes possuem. Aliás, o próprio Conselho Regional de Educação Física, valoriza o profissional de educação física neste sentido e enfatiza a importância da identificação do contexto onde a prática esportiva irá acontecer, já que cada uma das formas que o esporte é praticado, pode apresentar metodologias e abordagens diferentes (CREF9/PR, 2020, p.1).

A seguir passo a apresentar e discutir elementos abordados na pesquisa propriamente dita, tendo sido esta realizada com 1.232 praticantes de voleibol residentes em todo país. Para alcançar esta abrangência, foram contatados professores de educação física e técnicos de voleibol de todos os estados brasileiros. Para estes, após breve apresentação das intenções da pesquisa, foi solicitado que encaminhassem para suas redes de contato um breve texto explicativo sobre o estudo e o link para que um questionário fosse respondido pelos praticantes de voleibol que se enquadravam no público alvo da pesquisa. 0 questionário foi disponibilizado no Google Forms e pôde ser respondido ao longo de uma semana.

\section{A PESQUISA}

Inicialmente, os respondentes deveriam sinalizar se estariam sentindo falta da prática regular de voleibol em decorrência do período de isolamento social e suspensão temporária das práticas esportivas coletivas em todo o país. Entre os entrevistados, 99\% deles sinalizaram que estavam sentindo falta do voleibol. Esse dado inicial aponta claramente como há um envolvimento significativo destas pessoas com esta modalidade esportiva e como estas dão importância para suas rotinas de vida vinculadas à tais práticas. Procurando entender um pouco melhor sobre quão significativa poderia ser a falta do voleibol para estas pessoas, a pesquisa buscou saber especificamente se isso teria sido uma das coisas que mais estariam fazendo falta durante o isolamento social, se comparado a outros tipos de atividades e ocupações.

Gráfico 1: 0 que você mais sentiu falta no isolamento social?

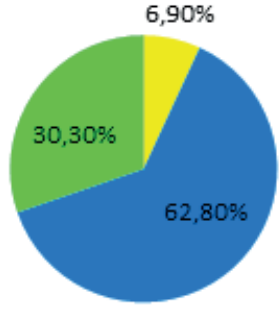

O esporte de fato é um fenômeno social que tem importância singular na sociedade, fazendo parte da cultura dos brasileiros. Tendo mais de $30 \%$ dos entrevistados registrado que o que mais sentiram falta no isolamento social havia sido o voleibol e outros $62,8 \%$ afirmado que a ausência de prática deste esporte representou uma das três coisas que mais sentiram falta, é possível supor, conforme Silva e Oliveira (2012, p.1) que estas pessoas percebem estes momentos que foram privadas como momentos de diversão, de desenvolvimento de suas habilidades motoras, físicas e mentais, superação de desafios e ainda amizade.

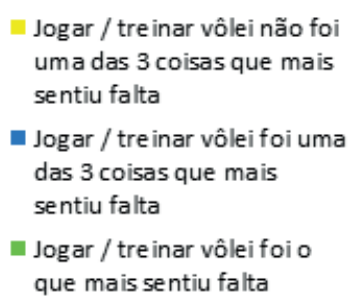

Perguntados se durante o isolamento social a prática do voleibol teria sido substituída por outra forma de atividade física ou de lazer, os resultad os foram os seguintes:

A distribuição um pouco mais equilibrada nas respostas indica que a maior parte das pessoas não parou de realizar atividades físicas, sejam exercícios físicos $(42,5 \%)$ ou atividades físicas de lazer em suas próprias casas (21,8\%). 0 percentual de pessoas que não realizaram qualquer tipo de atividades físicas, porém, não pode ser desprezado, afinal os $35,6 \%$ se referem a 439 pessoas. Talvez a justificativa para este índice de inatividade física esteja relacionada ao fato de que nem sem- 
Gráfico 2: No isolamento social suas práticas de vôlei foram substituídas por outra atividade?

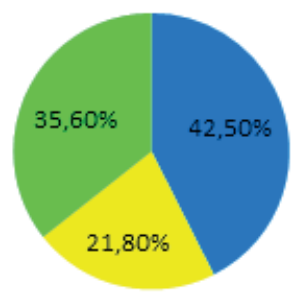

Sim. Outras formas de atividades físicas (exercícios físicos)

Sim. Outras formas de lazer (atividades físicas de lazer em casa)

não realizei outras atividades

pre as atividades físicas ou exercícios físicos realizados durante o período de isolamento social tenham provocado o bem-estar. Foi isso que pesquisadores de três universidades conceituadas do Brasil descobriram a partir de uma pesquisa realizada neste contexto. Segundo estes pesquisadores, a prática do exercício físico realizada no período de isolamento social com objetivos de manutenção da forma, mesmo sendo um hábito saudável, nem sempre tem se apresentado como benéfica a saúde mental (UERJ, 2020). Uma das justificativas apresentadas pelos pesquisadores parece combinar com o que aconteceu com praticantes de voleibol: "o que fica claro é a importância de não se alterar drasticamente a rotina e os hábitos de antes da quarentena, pois essa mudança gera mais ansiedade e, consequentemente, mais adoecimento mental" (UERJ, 2020, p. 1). Considerando as características do jogo de voleibol como o número de participantes, a necessidade de um espaço grande, plano e livre de obstáculos e também de uma rede, somados a dinâmica do jogo, é compreensível que os praticantes deste esporte não tiveram muitas opções para continuar realizando suas práticas, salvo realizando grande adequação e criatividade.

Quem sabe esta dificuldade em adaptar uma ou outra atividade ligada ao voleibol no período de isolamen- to social tenha refletido no que seus praticantes afirmaram em relação a sua motivação para praticar esse esporte, já que 1.045 dos entrevistados (84,8\%) afirmaram que o isolamento social fez com que eles valorizassem mais ainda suas práticas ligadas ao voleibol. Parece ganhar espaço aqui o que aquele velho dito popular anuncia: "as coisas passam a ter valor quando se perdem”. É provável que o grau de valorização dada à prática do voleibol passou a ser maior a partir do momento em que as pessoas tiveram que se abster deste esporte. Apenas 3,5\% dos entrevistados relataram que o isolamento social não fez com que valorizassem mais suas práticas no voleibol. Outros $11,7 \%$ responderam que era indiferente.

O estudo verificou também se o isolamento social poderia ter evidenciado ou não alguma possível relação entre a prática do voleibol e a qualidade de vida.

Nesta questão, 1.048 sujeitos $(85,1 \%)$ responderam que os treinos e jogos de voleibol são muito importantes para sua qualidade de vida. Outros $161(13,1 \%)$ registraram que eram parcialmente importantes. Apenas 23 $(1,9 \%)$ responderam que os treinos não eram importantes. A expressividade de respostas manifestada acenando para a importância do voleibol para a qualidade de vida de seus praticantes corrobora com o que Krebs destaca:

\section{Gráfico 3: Em relação a sua qualidade de vida, o isolamento social} e afastamento dos treinos/jogos de vôlei mostrou que:
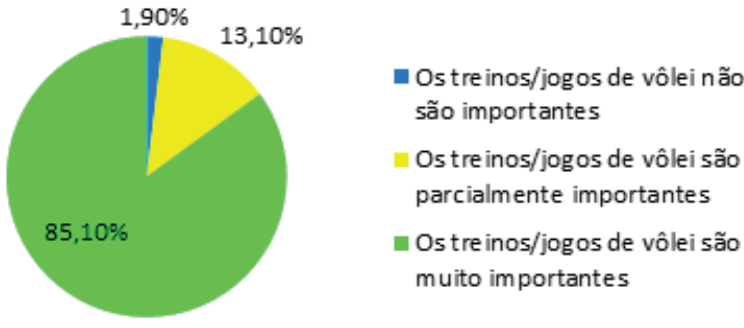
Deu modo um tanto simplista, o esporte tem sido mostrado como o caminho para todos aqueles que buscam uma melhor qualidade de vida. Todos os benefícios da prática esportiva têm sido usados para ilustrar um estilo de vida mais ativa, necessário para que o ser humano desse milênio vença a batalha contra o sedentarismo, causador de tantos males à saúde (KREBS, 2002, p. 22)

Tubino (2002) enfatiza que questões relacionadas à qualidade de vida são complexas e envolvem aspectos como segurança, saneamento, educação, habitação, trabalho, moradia, poder aquisitivo, saúde e lazer entre outros. Tais aspectos integrados ao estilo de vida ativo das pessoas podem interferir positivamente na qualidade de vida destas. Enquanto alguns destes aspectos não dependem unicamente dos próprios sujeitos, como questões de saneamento, qualidade do ar e segurança, por exemplo, o estilo de vida ativo por meio da prática do voleibol, pelo contrário, depende de opções e interesses individuais. Esta escolha pode ser um dos pilares responsáveis pela qualidade de vida, dependendo apenas de cada um. Com a necessidade do isolamento social e a proibição do trânsito livre para práticas esportivas, também o estilo ativo dos praticantes de voleibol sofreu interferência externa, não dependendo mais somente de interesses individuais. Desta forma, esse aspecto importante para a qualidade de vida - estilo ativo - parece ter pesado ainda mais entre os "voleibolistas".

Conhecendo as diversas motivações que podem estar inseridas na adesão de praticantes de voleibol por tais práticas, a pesquisa buscou compreender o que estaria fazendo mais falta para estes, a saber: a) Atividades físicas para manutenção da saúde (saúde Física); b) Atividades de lazer e descontração (saúde mental); c) Atividades de convívio social (socialização); d) Desenvolvimento técnico (performance).

Gráfico 4: Com a ausência das atividades ligadas ao vôlei, quais dos aspectos estão fazendo mais falta para você?

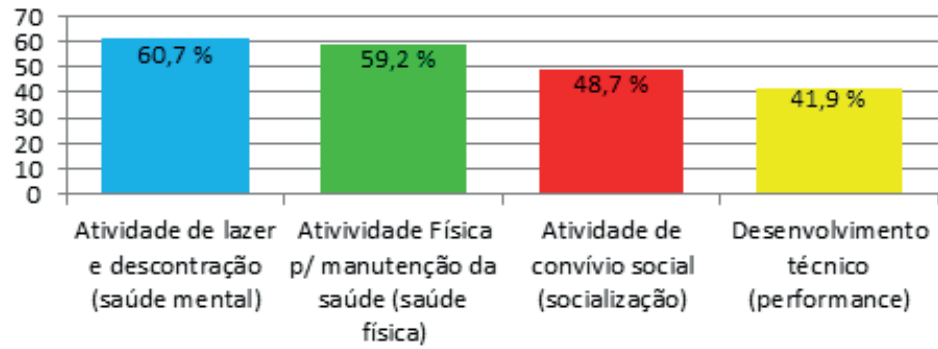

0 equilíbrio encontrado nas respostas nesta parte da pesquisa chama atenção. Como destacado ao longo do estudo, várias podem ser as motivações que levam as pessoas a procurar por espaços para a prática de voleibol ou grupos fechados para participar, porém, o fato de existir tamanha diversidade e equilíbrio de opiniões nas respostas confirma como tais práticas agregam adeptos com objetivos diversificados ao mesmo tempo, muitas vezes nos mesmos grupos. As atividades de lazer e descontração (saúde mental) foram o aspecto que mais estaria fazendo falta aos praticantes de voleibol $(60,7 \%)$. Ao tratar sobre "saúde mental", no entanto, é preciso dizer que o avanço da pandemia no Brasil e no mundo, somados ao excesso de informações disponíveis, por vezes até contraditórias, formaram um ambiente de preocupação e alterações comportamentais que podem oca- sionar consequências para a saúde mental (LIMA et al. 2020). Mesmo afirmando que há uma escassez de estudos sobre as implicações da pandemia do novo coronavírus sobre a saúde mental, principalmente em virtude de ser um fenômeno recente, Schmidt (2020) afirma que podem ocorrer repercussões negativas significativas. Complementa afirmando que:

\footnotetext{
A rápida disseminação do novo coronavírus por todo o mundo, as incertezas sobre como controlar a doença e sobre sua gravidade, além da imprevisibilidade acerca do tempo de duração da pandemia e dos seus desdobramentos, caracterizam-se como fatores de risco à saúde mental da população geral (ZANDIFAR \& BADRFAM apud. SCHMIDT et al. 2020, p.1).
}

É sabido que um dos benefícios que a prática dos esportes pode proporcionar está ligada aos benefícios 
para a saúde mental, catalisando emoções, atuando como atividades de "antiestresse" e provocando bem-estar. Como lembra Nahas (2010), as atividades físicas desenvolvidas como lazer podem agregar benefícios para a saúde física e mental. Há evidências também de que atividade física melhora a autoestima, autoconceito, diminui o estresse e a ansiedade. A realização de comportamentos saudáveis termina sendo o principal caminho para otimizar a saúde mental (OLIVEIRA et al., 2011).

Estando já preocupados com a situação provocada pela pandemia, não é estranho que os esportistas, longe de suas rotinas, terminem sentindo falta de atividades que promovam o lazer e a descontração, agregando benefícios à sua saúde mental.

Com quase o mesmo grau de importância, os praticantes de voleibol relataram que estão sentindo falta de atividades do voleibol direcionadas a saúde física $(59,2 \%)$. 0 jogo de voleibol é caracterizado por momentos de alternância de esforço de seus jogadores, podendo existir momentos curtos de grande esforço e outros períodos de movimentos de pequena intensidade ou até repouso. Mesmo a pesquisa não tendo sido desenvolvida com atletas profissionais, é possível afirmar que no vôlei, qualidades físicas como a agilidade, velocidade, equilíbrio e força explosiva são essenciais para que seus praticantes possam executar bem os fundamentos do jogo e obterem um bom desempenho. Ao praticarem o voleibol, os praticantes desta modalidade se exercitam, agregando benefícios para sua saúde física. É sabido que a prática regular de esportes proporciona benefícios para o sistema cardiorrespiratório, desenvolve grupos musculares, melhora a circulação sanguínea e ainda pode fazer reduzir o risco do desenvolvimento de algumas doenças. Forçados a suspender suas práticas habituais de voleibol, não causa estranheza os esportistas sentirem falta das atividades voltadas a saúde física. Ferreira et. al. (2020) contextualizando as atividades físicas durante a pandemia da Covid-19 lembra da importância destas para a melhora da imunidade.

Diante das recomendações de isolamento social atualmente impostas em vários países, incentivar a manutenção de uma rotina de vida fisicamente ativa por parte da população como uma medida preventiva para a saúde é fundamental durante esse período de enfrentamento contra a disseminação do vírus (FERREIRA et. Al., 2020, p. 1).
Outro aspecto lembrado foi a falta de atividades esportivas para o convívio social. Foram 601 respostas que apontaram para isso, o que corresponde a $48,7 \%$ do total, ou seja, representam quase a metade das opiniões. Por seu caráter eminentemente coletivo, o voleibol termina sendo uma das modalidades esportivas mais procuradas por pessoas que buscam uma atividade de lazer com o intuito de formar laços de amizade ou apenas se divertir em grupo. Krebs inclusive realiza um pertinente comentário articulando a importância dos relacionamentos interpessoais para a qualidade de vida no esporte. Segundo este autor,

Devemos resgatar a noção de que a qualidade de vida através do esporte não depende exclusivamente do ambiente físico, mas principalmente da qualidade das relações interpessoais estabelecidas entre os praticantes, da relevância que a prática assume para eles e das expectativas impregnadas nos papeis desempenhados por todas as pessoas envolvidas (KREBS, 2002, p. 23).

Imagina-se que a maioria destes esportistas não estão envolvidos nesses grupos de voleibol com o desejo de superar seus limites ou mensurar forças com adversários, mas para sentirem-se satisfeitos pela convivência com outras pessoas, estando inseridos em uma estrutura organizada com segurança onde aproveitam satisfatoriamente o convívio social (Almeida e Gutierrez, 2008).

Por final, também foi lembrado por um número razoável de voleibolistas $(41,9 \%)$ a falta que as práticas ligadas ao desenvolvimento técnico e performance no voleibol estavam fazendo. Mesmo estes grupos/equipes de voleibol não se constituírem como esporte de alto rendimento, "esporte espetáculo", preferido das mídias por sua vocação mercadológica, jogadas sensacionais e consagração de ídolos, alguns de seus praticantes, terminam sofrendo influências deste formato de esporte. Como descrito anteriormente, a condição técnica e habilidade dos jogadores pode tornar a prática mais interessante e valorizada por todos. Assim, a preocupação com uma eventual queda de performance também se mostrou presente entre os praticantes de voleibol, mesmo que em uma escala menor.

A parte final da pesquisa procurou saber especificamente se a ausência da prática de voleibol poderia ter interferido ou não nos seguintes aspectos da vida dos esportistas: a) Qualidade do sono; b) Manutenção do peso; c) Estado de humor; d) Nível de estresse; e) Sentimento de felicidade e realização. 


\section{Gráfico 5: A ausência dos treinos/jogos de voleibol interferiram em algum dos aspectos destacados? Em caso afirmativo, quais?}

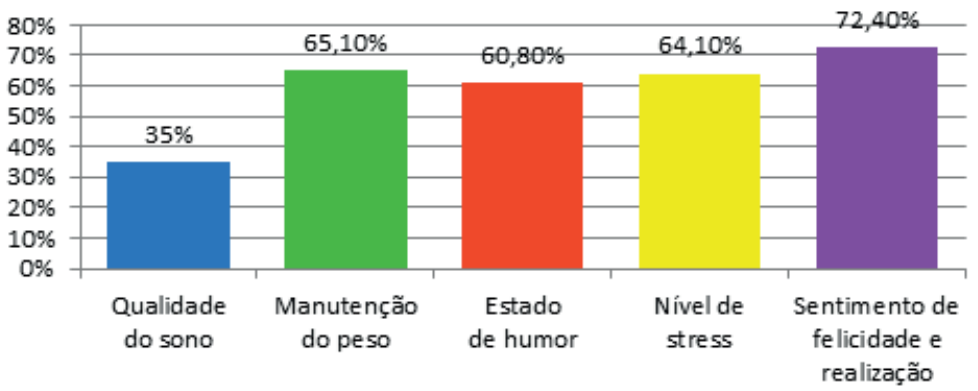

Uma primeira análise do gráfico, combinada com o que as análises anteriores evidenciaram, mostra o tamanho do impacto que a falta da prática regular de voleibol, em decorrência do isolamento social, provocou aos esportistas. 0 aspecto menos referido nesta etapa da pesquisa foi sobre a qualidade do sono, mesmo assim, foram 422 respostas (35\%) que sinalizaram isso. Outra pesquisa realizada no Brasil trouxe números ainda maiores sobre isso, registrando que neste momento de pandemia, um total de $44 \%$ dos entrevistados estariam com dificuldades em dormir. As razões para isso podem passar pela mudança de rotina das pessoas, os níveis de ansiedade aumentados e a diminuição ou suspenção das atividades físicas ou esportivas, como percebidos nos participantes deste estudo.

Todos os outros aspectos foram sinalizados pela maioria dos respondentes, com índices sempre acima dos 60\%. A ausência da prática regular de voleibol interferiu no humor de 733 pessoas $(60,8 \%)$. Ficando evidenciada ao longo da pesquisa como a prática do voleibol tem relevância para estes esportistas, dada sua significância para a qualidade de vida destes e falta que está fazendo no período de isolamento social, não se estranha que exista alteração de humor entre os indivíduos pesquisados.

Oliveira et al. (2011, p. 129) afirma ser consenso os efeitos nocivos do estresse sobre o organismo e os benefícios da atividade física no combate ao estresse. 0 nível de estresse entre os esportistas pesquisados aumentou em larga escala durante o isolamento social e suspensão das práticas ligadas ao voleibol, uma vez que 772 deles afirmaram isso $(64,1 \%)$. Os dados construídos se aproximam do estudo que Bezerra et al. (2020) realizaram sobre o grau de estresse durante a pandemia e isolamento social. A referida pesquisa indicou que $73 \%$ das pessoas manifestaram algum grau de estresse, porém entre pessoas que realizam atividades físicas, esse índice apresenta-se 13\% menor. Tais evidências indicam que, mesmo estando os praticantes de voleibol com níveis de estresse mais altos que habitualmente, o fato de seguirem uma prática regular de atividades físicas e esportes antes da pandemia ou de seguirem com outras atividades de lazer ou exercícios físicos em casa nesse período (64\%), pode estar auxiliando no alívio das tensões do dia a dia, fazendo o grau de estresse não ser mais elevado ainda.

Na segunda colocação, no que tange ao aspecto que estaria mais sofrendo interferência em decorrência da suspensão da prática do voleibol durante o isolamento social, os esportistas afirmaram ser a manutenção do peso. Esse ponto foi indicado por 785 participantes da pesquisa $(65,1 \%)$. Não por acaso, a ausência de atividades físicas para a manutenção da saúde física foi uma das maiores preocupações dos esportistas. A prática moderada de voleibol queima entre 292 e 364 calorias em uma hora em um adulto ${ }^{7}$ (Galileu, 2017). Com a ausência das atividades ligadas ao voleibol, é provável que boa parte dos esportistas tenham tido dificuldade em manter seu peso ideal, justificando tamanha importância que esse aspecto acabou recebendo.

Por final, o aspecto com maior índice de respostas entre os esportistas se referiu ao sentimento de felicidade e realização ${ }^{8}$. Marques (2007), ao comentar que o estilo de vida ativo normalmente está relacionado à qualidade de vida e saúde, destaca que o meio social

70 gasto total de calorias em uma atividade física ou esportes depende de vários fatores, podendo modificar de acordo com a idade, sexo, estatura, massa muscular e ainda fatores genéticos. 8 Realização pessoal. 
também se relaciona com a felicidade. 0 total de 873 esportistas $(72,4 \%)$ afirmaram que estavam menos felizes e realizados em virtude da ausência de suas atividades ligadas ao voleibol. Reconhecendo a proximidade entre "felicidade" e "bem-estar" aproprio-me do que Oliveira et al. (2011) retratam sobre a importância da prática de atividades físicas para o bem-estar. Para estes autores, as atividades físicas podem estar relacionadas de modo positivo com o bem-estar físico, emocional e também psíquico das pessoas em ambos os sexos, em todas as idades. Outra pesquisa relacionada ao tema, realizada nos Estados Unidos, compara o sentimento de "satisfação com a vida" de acordo com a quantidade de atividades físicas que as pessoas tenham realizado em um dia, independente do tipo de atividade física ou esporte. Os resultados indicaram que quanto mais atividades físicas tenham sido desenvolvidas, maior a satisfação com a vida e bem-estar (MAHER et. Al., 2013). De mesmo modo como nesta pesquisa destacada, os praticantes de voleibol brasileiros, acostumados com suas práticas regulares do esporte, sinalizaram que com a suspensão das atividades devido ao isolamento social, passaram a se sentir menos realizados e felizes.

\section{PONTOS FINAIS}

Em decorrência da preocupação com a pandemia do novo coronavírus, em todo o mundo diferentes medidas de prevenção ao vírus e cuidados foram estabelecidas, mesmo que por vezes diferentes em cidades, estados e países. 0 isolamento social, no entanto, foi uma das práticas mais recomendadas e adotadas, sendo indicada pela OMS, ONU e OPAS. No mês de abril de 2020, de acordo com a $\mathrm{AFP}^{9}$, aproximadamente 4,5 bilhões de pessoas estavam vivendo em isolamento social, número justificável dado o alto número de pessoas infectadas pelo novo coronavírus e óbitos ocorridos até então.

A presente pesquisa buscou conhecer os impactos do isolamento social sobre praticantes de voleibol adultos, acreditando serem estes esportistas um dos grupos que mais possam ter sentido alterações em suas rotinas de vida e hábitos, quando foram obrigados a suspende-

9 A Agence France Presse (AFP), localizada em Paris, França, é considerada uma das agências de notícias de maior prestígio no mundo. rem temporariamente suas atividades esportivas. Mais do que confirmar a premissa inicial, o desenvolvimento do estudo apresentou importantes informações.

A modalidade de voleibol se confirmou como uma prática esportiva que congrega um número elevado de esportistas que apresentam, por sua vez, uma variedade de motivações relacionadas à sua prática. $\mathrm{O}$ isolamento social evidenciou como estas práticas são importantes para os esportistas que participaram da pesquisa. Buscando evidenciar quais aspectos ligados as práticas regulares do voleibol estariam fazendo mais falta para estes, o estudo sinalizou que foram as atividades de lazer e descontração voltadas à saúde mental. Quase com o mesmo volume de respostas, os esportistas alegaram também que sentiam falta do voleibol como meio de manterem ou desenvolverem sua saúde física. A importância demonstrada a aspectos ligados à saúde pôde também ser evidenciada a partir da sinalização que os esportistas deram sobre as alterações em seu peso corporal, nível de estresse e estado de humor quando estiveram sem praticar o voleibol.

Outro aspecto apresentado com relativa importância foi a identificação do voleibol como meio de socialização, talvez reforçado pelo período de reclusão e confinamento provocados pela pandemia. Ao contrário do esporte de alto rendimento, a preocupação com a possível queda de qualidade técnica com a suspensão das atividades ligadas ao voleibol, não se mostrou tão efetiva na pesquisa. Evidencia-se assim como a presença e preparo de um profissional que possa estar à frente destes grupos é fundamental, atendendo a diversidade de expectativas, propondo diferentes abordagens, dinâmicas, atividades e treinos de voleibol que possam assegurar a satisfação dos participantes.

As análises finais apontam para a importância destacada que as práticas do voleibol possuem na vida dos sujeitos participantes da pesquisa. Tais práticas, além de todos os benefícios identificados no estudo, provocam a sensação de bem-estar, felicidade e realização entre os esportistas, sentimentos e sensações diminuídos durante o período do isolamento social e abstenção deste esporte. Finalmente, é possível afirmar que a suspensão das práticas de voleibol em decorrência do isolamento social provocado pela pandemia da Covid-19, causou diferentes impactos na vida de esportistas que praticavam o voleibol regularmente. 


\section{REFERÊNCIAS}

ALMEIDA, M, A, B. GUTIERREZ, G, L. A nova dimensão esportiva: Uma leitura do esporte e do lazer. EFDeportes.com, Revista Digital. Buenos Aires, no 116, jan. 2008. http://www.efdeportes.com/efd116/uma-leitura-do-esporte-e-do-lazer.htm

ANJOS, Leandro Pereira dos. 0 esporte como lazer. Disponível e m: h t tps: / / universidaded of u tebol.com. br/o-esporte-como-lazer/. Acesso em: 2 jul. 2020.

ALVES, Jéssica. Esportes mais populares no Brasil. Guia Estudo. Disponível em: https://www.guiaestudo.com.br/esportes-mais-populares-no-brasil. Acesso em: 2 jul. 2020.

BENVENUTO, Domenico; GIOVANNETTI, Marta; CICCOZZI, Alessandra; SPOTO, Silvia;

ANGELETTI, Silvia; CICCOZZI, Massimo. The 2019-new coronavirus epidemic: evidence for virus evolution. Journal Medical Virology, p.1-5, 2020. Disponível em: https://www.arca.fiocruz.br/bitstream/icict/40020/2/MartaGiovanetti_MassimoCiccozzi_etal_IOC_2020.pdf. Acesso em: 29 jun. 2020.

BEZERRA, Anselmo C. Vasconcelos; SILVA, Carlos E. Menezes da; SOARES, Fernando R. Gameleiras; SILVA, José A. Menezes da. Fatores associados ao comportamento da população durante o isolamento social na pandemia de COVID-19. Ciência e Saúde Coletiva. Rio de Janeiro, vol.25, jun. 2020.

BRACHT, V. Esporte, Estado, sociedade. Revista Brasileira de Ciências do Esporte, Campinas, v.10, n.2, p.69-73, 1989.

CONSELHO REGIONAL DE EDUCAÇÃO FÍSICA DO PARANÁ CREF9/PR. Disponível em: http://www.crefpr.org.br/ noticias/o-ensino-do-esporte-como-prerrogativa-do-profissional-de-educacao-fisica. Acesso em: 3 jul. 2020.

FERREIRA, Maycon Junior; IRIGOYEN, Maria Cláudia; COLOMBO, Fernanda Consolim; SARAIVA, José F. Kerr; ANGELIS, Kátia de. Vida Fisicamente Ativa como Medida de Enfrentamento ao COVID-19. Sociedade Brasileira de Cardiologia. Arq. Bras. Cardiologia, 2020. Disponível em: https://doi.org/10.36660/ abc.20200235. Acesso em: 22 jul. 2020.

FUNDAÇÃO Oswaldo Cruz. Impactos sociais, econômicos, culturais e políticos da pandemia. Disponível em: https://portal.fiocruz.br/impactos-sociais-economicos-culturais-e-politicos-da-pandemia. Acesso em: 30 jun. 2020.

GALILEU. Descubra quantas calorias você perde praticando 39 exercícios diferentes. Revista Galileu, out. 2017. Disponível em: https://revistagalileu.globo.com/Ciencia/noticia/2017/10/ descubra-quantas-calorias-voce-perde-praticando-39-exercicios-diferentes.html. Acesso em: 21 jul. 2020.

KREBS, Ruy Jornada. Esporte, meio ambiente e Qualidade de Vida: um entrejogo mediado pela perspectiva ecológica. In: MOREIRA, Wagner Wey; SIMÕES, Regina (orgs). Esporte como fator de Qualidade de Vida. Piracicaba: Editora UNIMEP, 2002, p. 17-24.
LEWIS, Tanya. How Coronavirus Spreads through the Air: What We Know So Far. Scientific American. Mai. 2020. Disponível em: https://www.scientificamerican.com/article/how-coronavirus-spreads-through-the-air-what-we-know-so-far1/. Acesso em: 19 jul. 2020

LIMA, Carlos K. Tavares; CARVALHO, Poliana M. de M.; LIMA, Igor de A. A. Silva; NUNES, José V. A. de 0; SARAIVA, Jeferson Steves; SOUZA, Ricardo I. de; SILVA, Claudio G. L da; NETO, Modesto L. Rolim. The emotional impact of Coronavirus 2019-nCoV (new Coronavirus disease). In: Psychiatry Research, vol. 287, p. 1-2, 2020. Disponível em: https://doi.org/10.1016/j.psychres.2020.112915. Acesso em: 21 jul. 2020.

MAHER, J. P; DOERKSEN, S. E., ELAVSKY, S., HYDE, A. L., PINCUS, A. L., RAM, N., \& CONROY, D. E. A daily analysis of physical activity and satisfaction with life in emerging adults. Health Psychology, 32 (6), p. 647-656, 2013. Disponível em: https://doi. org/10.1037/a0030129. Acesso em: 24 jul. 2020

MARQUES, Renato Francisco Rodrigues. Esporte e qualidade de vida: reflexão sociológica. Dissertação de mestrado. Universidade Estadual de Campinas. Campinas/SP: 159p, 2007.

MINISTÉRIO da Saúde. Brasil confirma primeiro caso da doença. Disponívelem: https://www.saude.gov.br/noticias/agencia-saude/46435-brasil-confirma-primeiro-caso-de-novo-coronavirus. Acesso em: 30 jun. 2020.

MINISTÉRIO da Saúde. Painel de controle da epidemia da Covid-19. Disponível em: https://covid.saude.gov.br/. Acesso em: 10 ago. 2020.

MEDEIROS, Eduardo A. Servolo. Desafios para o enfrentamento da pandemia Covid-19 em hospitais universitários. São Paulo: Rev. Paulista Pediatria. Vol. 38, Abr. 2020.

MOREIRA, Tatiana Sviesk; MEZZADRI, Fernando Marinho; SOUZA, Doralice Lange de; SILVA, Marcelo Moraes e. 0 perfil da produção científica em língua portuguesa sobre o voleibol. Motrivivência: Florianópolis/SC, v. 29, n. 51, p. 119-135, jul. 2017

MUNIZ, Igor Barbarioli. A experiência da derrota no esporte contemporâneo. Revista EFDeportes. Buenos Aires: Ano 15, no 147, ago, 2010.

NAHAS, M. V. Atividade física, saúde e qualidade de vida: conceitos e sugestões para um estilo de vida ativo. $5^{\mathrm{a}}$ ed. Londrina: Midiograf, 2010.318p.

OLIVEIRA, Eliany N.; AGUIAR, Rômulo Carlos de; ALMEIDA, Maria Tereza O. de; ELOIA, Sara Cordeiro; LIRA, Tâmia Queiroz Benefícios da Atividade Física para Saúde Mental. Saúde Coletiva. São Paulo: Ed. Bolina, vol. 8, no 50, p. 126-130, 2011.

ONU News. Opas diz que Brasil deve intensificar isolamento social para conter pandemia. Disponível em: <https://news un.org/pt/story/2020/05/1714482>. Acesso em 30 jun. 2020 . 
PIRES, Roberto Rocha C. Os efeitos sobre grupos sociais e territórios vulnerabilizados das medidas de enfrentamento à crise sanitária da covid-19: propostas para o aperfeiçoamento da ação pública. Nota Técnica. IPEA. Brasília, DF: 2020. Disponível em: http://repositorio.ipea.gov.br/handle/11058/9839. Acesso em: 19 jul. 2020

ROTTMANN, Hans Gert. Esportes e atividades físicas na quarentena. Revista Mundo Esportivo. São Leopoldo. Ed. 397, p. 12, Mai. 2020.

SANTOS, Ana Lucia Padrão dos; SIMÕES, Antonio Carlos. Educação Física e Qualidade de Vida: reflexões e perspectivas, Saúde Soc. São Paulo, v.21, n.1, p.181-192, 2012.

SCHMIDT, Beatriz; CREPALDI, M ${ }^{\text {a }}$ Aparecida; BOLZE, Simone D. A.; NEIVA-SILVA, Lucas; DEMENECH, Lauro M. Saúde mental e intervenções psicológicas diante da pandemia do novo coronavírus (COVID-19). Estudos de Psicologia. Campinas, no 37 , 2020. Disponível em: https://www.scielo.br/pdf/estpsi/v37/ 1678-9865-estpsi-37-e200063.pdf. Acesso em: 20 jul. 2020
SILVA, Alan F. da; OLIVEIRA, Adriana L. Os benefícios da prática esportiva e do exercício para a saúde e qualidade de vida do indivíduo. Universidade de Taubaté. Encontro Latino Americano de Pós Graduação, 2012. Disponível em: http:// www.inicepg.univap.br/cd/INIC_2012/anais/arquivos/0621_0243_01. Acesso em: 20 jul. 2020.

TAN, WJ; ZHAO X, MAXJ. A novel coronavirus genome identified in a cluster of pneumonia cases: Wuhan, China 2019-2020. China CDC Weekly 2020; 2:61-2.

BELASCO, Angelica Gonçalves Silva; FONSECA, Cassiane Dezoti da. Coronavírus 2020. Rev. Bras. Enferm. Brasília: Vol.73, nํ․2. Mar, 2020.

UERJ. Pesquisa da UERJ avalia os efeitos da atividade física no bem-estar das pessoas em quarentena. Diretoria de Comunicação da UERJ. Universidade do Estado do Rio de Janeiro (UERJ); Universidade Federal do Ceará (UFCE); Pontifícia Universidade Católica do Rio de Janeiro (PUC-Rio). Disponível em: https:// www.uerj.br/noticia/pesquisa-da-uerj-avalia-os-efeitos-da-atividade-fisica-no-bem-estar-das-pessoas-em-quarentena/. Acesso em: 17 jul. 2020. 